\title{
Predictive Value of Estimated Beta
}

\author{
Amarjit Gurbuxsh Singh \\ Westcliff University
}

\section{ABSTRACT}

The Capital Asset Pricing Model (CAPM) is widely used in corporate finance to assess expected returns of securities and return on equity, and beta, a measure of systematic risk, is a component of the CAPM equation. Previous studies appear not to have addressed whether beta as a stand-alone metric allows individual investors to effectively assess returns relative to the market, and this study aims to address this. Exchange-traded funds (ETFs) reflecting a range of expected volatilities relative to the S\&P 500 index were selected. Betas of XLK (Technology sector), XLE (Energy sector), XLU (Utilities sector), and XLY (Consumer Staples sector) were estimated by regressing their weekly returns over five years against those of the S\&P 500 index. Three five-year periods were used (ending in 2005, 2010, and 2015). The betas largely conformed to anticipated values with the exception of that of XLY which was surprisingly greater than the market beta. Estimated and observed betas were compared using a two-tailed paired T-test and no difference was found, suggesting that estimated beta is statistically a good proxy for actual beta. In practical terms though, there were relatatively large variances in several instances between estimated and observed betas, and this could be a concern for investors. Returns using estimated beta and actual returns were also compared over one, two, three, four, and five years with regard to the three five-year periods. Significant variation was observed for expected minus observed returns both in sign and magnitude. A two-tailed paired T-test suggested there was a difference between returns using estimated beta and actual ones over the three five-year periods for all funds except XLE. The observations suggest betas are volatile and individual investors should incorporate additional metrics to forecast returns relative to the market.

Keywords: beta, Capital Asset Pricing Model (CAPM), individual investor, sector funds, volatility transmission

\section{Predictive Value of Estimated Beta}

The riskiness of a portfolio is an important consideration for an investor. Standard deviation and variance are measures of absolute risk (Baltuttis et al., 2020). These measure volatility, but a better context is provided if volatility of a portfolio is benchmarked relative to the market. Assuming the investor has fully diversified away unsystematic risk, the systematic risk, pertaining to the market as a whole can be measured by beta, which is incorporated in the Capital Asset Pricing Model (John, 2017).
The Capital Asset Pricing Model (CAPM), originating in 1965, is widely utilized, whether as theoretical underpinning in finance courses or applications in corporate finance. It is used to estimate the returns of portfolios adjusted for risk. In addition, corporations need to determine the weighted average cost of capital (WACC) in order to evaluate feasibility of capital projects (Khan et al., 2021). The WACC is used as a benchmark against the internal rate of return (IRR), or to discount cash flows of prospective projects to ascertain net present value (NPV) to evaluate attractiveness of capital projects. 
Capital structure varies across firms and industries, but typically, capital is raised by issuing some form of equity and debt. The cost of raising capital depends on the components of the capital structure and the cost of each component is factored into WACC. Common equity then, is usually an important component of capital structure, and its cost can be computed using the dividend growth model (Frank \& Shen, 2016).

However, in cases where a firm issues no dividends the CAPM model can be used, and as suggested by a study reviewed by Khan et al. (2021), the CAPM is the method most used by Chief Financial Officers for determining the cost of equity. The CAPM model can be described by (1), where $K_{e}$ is the cost of equity, $R_{f}$ is the riskfree rate, $R_{m}$ is the expected market return, $\left(R_{m}\right.$ $-R_{f}$ ) is the market risk premium, and $\beta_{\mathrm{e}}$ is the equity beta, denoting market risk (Chen, 2021; Finch et al., 2011; Graham \& Harvey, 2001). Ke can then be used to represent the cost of common equity in WACC.

$K_{e}=R_{f}+\beta_{e}\left(R_{m}-R_{f}\right)$ (1)

In addition to determining the cost of common equity, the CAPM equation can also be represented by (2), as follows, to compute the expected return on a security or portfolio. $\mathrm{R}_{\mathrm{i}}=R_{f}+\beta\left(R_{m}-R_{f}\right)$ (2)

In order for the CAPM to provide reliable estimates, three factors, the risk-free rate, the beta, and the expected market return have to be determined. The ease of assigning values to these variables has been questioned. For example, whether there exists an asset from which a risk-free rate of return could be established was a seminal criticism of the model, and this factor has been the focus of many studies scrutinizing the efficacy of the model (O'Sullivan, 2018). According to O'Sullivan (2018), subsequent criticisms have focused on two main strands; unsatisfactory performance of the model in empirical settings and the assumptions it rests on. Fama and French $(1993,1996)$ realized that both small firms as defined by market capitalization, and value firms, which had low market to book ratios, had higher performance than predicted by beta vis-à-vis that of their counterparts. The incorporation of two dependent variables to capture size and value, in addition to beta, forms the three-factor
CAPM model which made a limited improvement on the original one. Roll (1977), further deliberated on the empirical strand, questioning how the market portfolio, which is part of the portfolio, should be defined; for example whether or not returns on reputation and goodwill ought to be included.

Moving on to perceived theoretical flaws, a central assumption of the model is that investors are risk-averse; thus, compensation in the form of above-average returns is expected for riskier assets. O'Sullivan (2018) suggests that this assumption is axiomatic only. He posits that there is a wide spectrum of risk preferences in addition to risk aversion, and that the financial crisis of 2008 illustrated the risk appetite when sufficient gains could be contemplated.

\section{Objective of Study}

The CAPM's predictions have been falsified continually, but it remains a popular model. Brokerages and other personal finance websites that cater to the individual investor, however, do not expect the typical retail investor to use the full model by first estimating the variables that form the CAPM, and then compute expected returns across various portfolios. This is suggested by the fact that neither the equation nor the inputs to it are available on the websites.

The underpinnings of the CAPM are however, described by some brokerages. For example, Fidelity described factors with respect to the CAPM and its improved subsequent variations (Nielson et al., 2016). The article illustrated that factors such as size, value, momentum, quality, and low volatility could be weighted more in the portfolio to suit investing styles through the use of smart beta funds. There was no expectation though that the individual apply the CAPM model in one of its forms directly.

However, one element of the CAPM model, beta, is typically made available within standard quotes on personal finance sites such as Yahoo Finance, Marketwatch, MSN Money and Motley Fool, implying that the metric is of use as a singular measure. Beta is a measure of the systematic risk of the asset (Löffler \& Raupach, 2018). It affords an improved context for measurement of risk as investors are assumed to be rational and will have diversified 
away unsystematic risk. Assuming the investor is diversified and wishes to invest in the market fully cognizant of its vulnerabilities to economic, political and other events, beta should provide a meaningful measure of the volatility of the asset in relation to the market. Further, by removing the other factors viz. risk-free rate and expected market returns, the utility of beta as a standalone metric can be viewed.

The purpose of this study is not to evaluate whether asset returns adjusted for risk can be determined accurately via the CAPM model, but rather, whether beta as a singular measure, has practical value for investors in estimating volatility. The study will make a preliminary examination as to whether beta values, computed or extracted from websites, afford utility to the investor willing to bear a given systematic risk, and who can thereby employ the statistic to form a reasonable forecast of returns relative to market. By definition, the market has a beta of one, and a security with a beta of less than one will be expected to move in a narrower range than the market; whereas, a security with a beta greater than one would have magnified moves compared to the market (Anghel \& Paschia, 2013).

The following research questions $(R Q$ suffixed by its number) guide this study. Where a statistical test is used, only the null hypothesis, which is tested, is stated.

$R Q 1$ : "Do the beta values of the diversified portfolios reflect expectations?"

$\mathrm{RQ2}$. "Do the values of betas ex ante conform to those ex-post for diversified portfolios?"

Ho1. Estimated beta - observed beta for XLK (January 1, 2005 - December 31, 2010) $=0$

$H_{02}$. Estimated beta - observed beta for XLK (January 1, 2011 - December 31, 2015) $=0$

Ho3. Estimated beta - observed beta for XLK (January 1, 2016 - December 31, 2020) $=0$

$H_{0}$ 4. Estimated beta - observed beta for XLE (January 1, 2005 - December 31, $2010=0$

$H_{0} 5$. Estimated beta - observed beta for XLE (January 1, 2011 - December 31, 2015) $=0$
Ho6. Estimated beta - observed beta for XLE (January 1, 2016 - December 31, 2020) $=0$

$H_{0} 7$. Estimated beta - observed beta for XLU (January 1, 2005 - December 31, 2010) $=0$

$H_{0} 8$. Estimated beta - observed beta for XLU (January 1, 2011 - December 31, 2015) $=0$

$H_{0}$ 9. Estimated beta - observed beta for XLU (January 1, 2016 - December 31, $2020=0$

$H_{0} 10$. Estimated beta - observed beta for XLY (January 1, 2005 - December 31, 2010)

Ho11. Estimated beta - observed beta for XLY (January 1, 2011 - December 31, 2015)

Ho12. Estimated beta - observed beta for XLY (January 1, 2016 - December $31,2020)$

RQ3. "Do investments based on estimated betas generate returns close to those observed for the diversified portfolios over a five-year period?" RQ4: "Do returns from a diversified portfolio based on estimated beta provide a signal as to actual returns over a fifteen-year horizon?

$H_{0}$ 13. Returns using estimated beta observed returns for XLK (January 1 , $2005-$ December 31, 2020) $=0$ $H_{0}$ 14. Returns using estimated beta observed returns for XLE (January 1, $2005-$ December 31, 2020) $=0$ Ho15. Returns using estimated beta observed returns for XLU (January 1 , $2005-$ December 31, 2020) $=0$ $H_{0}$ 16. Returns using estimated beta observed returns for XLY (January 1 , $2005-$ December 31, 2020) $=0$

\section{Methods and Materials}

Kaplan and Peterson (1998) stressed that betas of individual firms reflect substantial statistical noise; estimating those of a portfolio of firms closely related with respect to business lines yields more precise values. This is supported by Damodaran (2001), who claimed that variation of industry betas is very low relative to that of company betas.

Extension of this reasoning suggests that a portfolio of numerous stocks, as opposed to single stocks within sectors will reflect a more 
stable beta. As noted by Liu et al. (2021), sector investing enhances diversification by leveraging risk and return profiles of particular industries. Frazzini and Pedersen (2014) contend that a large number of investors, such as individuals, pension funds, and mutual funds, necessarily overweight risky assets as they are unable to utilize debt. This further underlines the relevance of beta in portfolio construction.

Thus, if betas of specific sectors could reliably predict returns relative to the market, this would be of utility to the investor, as sector weightings could be meaningfully used as part of a diversification strategy while avoiding the risk of investing in single stocks. Sector funds would then, provide a good vehicle for the investor to execute this strategy. Exchange-traded funds (ETFs) seek to mimic the performance of an index (Lettau \& Madhavan, 2018). State Street Global Advisors affords a broad array of ETFs, and a sample was purposefully selected to sectors to represent a range of expected volatilities relative to the S\&P 500 index.

A recent study examined the relative volatility of sectors to that of S\&P 500 index (Investment Fidelity, 2018). The volatility of the S\&P 500 index was 15\% and the Information Technology and Energy sector were the most and second most volatile sectors with a volatility of $24.8 \%$ and $21.2 \%$ respectively. The Utility sector's volatility of $14.6 \%$ was closest to that of the index, while the Consumer Staples' sector volatility of $11.3 \%$ was the lowest. Accordingly, XLK (Technology Select Sector SPDR® Fund) and XLE (Energy Select Sector SPDR® fund) representing high volatility relative to the S\&P 500 index, XLU (Utilities Select Sector SPDR® Fund) representing similar volatility to the S\&P 500 index, and XLY (Consumer Discretionary Select Sector SPDR $\AA^{\circledR}$ Fund) representing low volatility relative to the S\&P 500 index were included in the sample to be studied.

Beta values are not stable and the sampling period used to estimate these is an additional variable in the usefulness of prediction. Aygören \& Saritaş (2007) used two three-stage methods for beta correction and found the adjustments significant and further, that longer time periods such as eight to nine years produced more accurate results. However, their sample includes 90 stocks listed on the Istanbul Stock Exchange (ISE) which may behave differently to larger and more transparent markets such as those represented by the S\&P 500 index. Further, the sample period covers June 1994 through June 2004 when market conditions may have diverged significantly from recent ones.

The study is through the lens of the individual investor who relies on beta quoted on personal finance websites; thus, consideration was given to how these compute beta, notwithstanding the fact that the methodology is not made easily available, if at all. However, according to a study by Coppedge et al. (2012), returns to estimate the coefficient were computed over 60 months by Value Line and Reuters, 36 months by Yahoo Finance and Smartmoney, and two years by Bloomberg. Bloomberg and Value Line employed weekly returns while the remainder used monthly ones over the respective periods. All five sites used the S\&P 500 as the benchmark with the exception of Value Line which used the NYSE Composite.

Cenesizoglu et al. (2016) suggest that the popular Fama-MacBeth beta from five years of monthly returns yields the most accurate forecast using monthly returns. Groenewold and Fraser (2000) acknowledge that the "five-year rule of thumb" is the most commonly used and most robust, but claim it is superseded by, in particular, a "three-year" model when techniques such as rolling regressions are incorporated. Further, Beer (1997) reviewed several techniques that attempted to correct beta and concluded that bias decreased only marginally.

The benefits of using corrective techniques have been mixed and context dependent. In this study, weekly returns over a five year period are employed as no adjustments or correcting techniques will be used. Moreover, weekly returns are used as this may provide a measure of improved precision over monthly returns.

Equation (2) can be represented as (3) and then simplified to (4) which can be used for regression.

$(1-\mathrm{b})+\beta\left(R_{m}\right)(3)$
$\mathrm{Rj}=\mathrm{a}+\beta R_{m}$

To address RQ1, betas were computed using regression analysis. The classical technique used to estimate the coefficient beta is regression, and the coefficient offers a 
measure of systemic risk (Cenesizoglu et al., 2017; Löffler \& Raupach, 2018). To aid in addressing $R Q 2$, estimated and observed betas were compared for statistical significance using a two-tailed paired T-test (Agarwal et al., 2018). In this study, the operator on each pair was assumed to be market conditions changing from one five-year period to the next five-year period. RQ3 will be assessed without a statistical test due to the small sample size involved. RQ4 will be evaluated for statistical significance by conducting a paired t-test to evaluate difference in returns over multiple periiods. This method was applied for example, to assess returns from smart beta funds over different period lengths (Verma et al., 2020).

\section{RQ1}

\section{Results}

Computed beta values are summarized in Table 1. In each case, the relationship of the ETF returns to those of the S\&P 500 index were significant, $p<0.05$. Figure 1 displays the beta variation across each period.

\section{Table 1}

Regression Analysis Summary for S \& P 500 Return Predicting Security Return

\begin{tabular}{lccc}
\hline Security & $\beta$ & $\mathrm{t}$ & $\mathrm{p}$ \\
\hline January 2001- & & & \\
December 2005 & & & \\
XLK & 1.41 & 22.06 & $<.001$ \\
XLE & 0.78 & 11.40 & $<.001$ \\
XLU & 0.60 & 11.15 & $<.001$ \\
XLY & 1.06 & 26.26 & $<.001$ \\
January 2006- & & & \\
December 2010 & & & \\
XLK & 0.92 & 34.19 & $<.001$ \\
XLE & 1.15 & 21.84 & $<.001$ \\
XLU & 0.68 & 17.73 & $<.001$ \\
XLY & 1.14 & 38.45 & $<.001$ \\
January 2011- & & & \\
December 2015 & & & \\
XLK & 1.03 & 37.84 & $<.001$ \\
XLE & 1.29 & 25.12 & $<.001$ \\
XLU & 0.44 & 8.77 & $<.001$ \\
XLY & 1.01 & 38.80 & $<.001$ \\
January 2016 - & & & \\
December 2020 & & & \\
XLK & 1.03 & 38.22 & $<.001$ \\
XLE & 1.21 & 16.99 & $<.001$ \\
XLU & 0.79 & 14.69 & $<.001$ \\
XLY & 1.06 & 44 & $<.001$ \\
\hline Note. Weekly returns for each five-year period for each \\
security were against the S\&P 500 index. &
\end{tabular}


Figure 1

Beta for Securities over Each Period

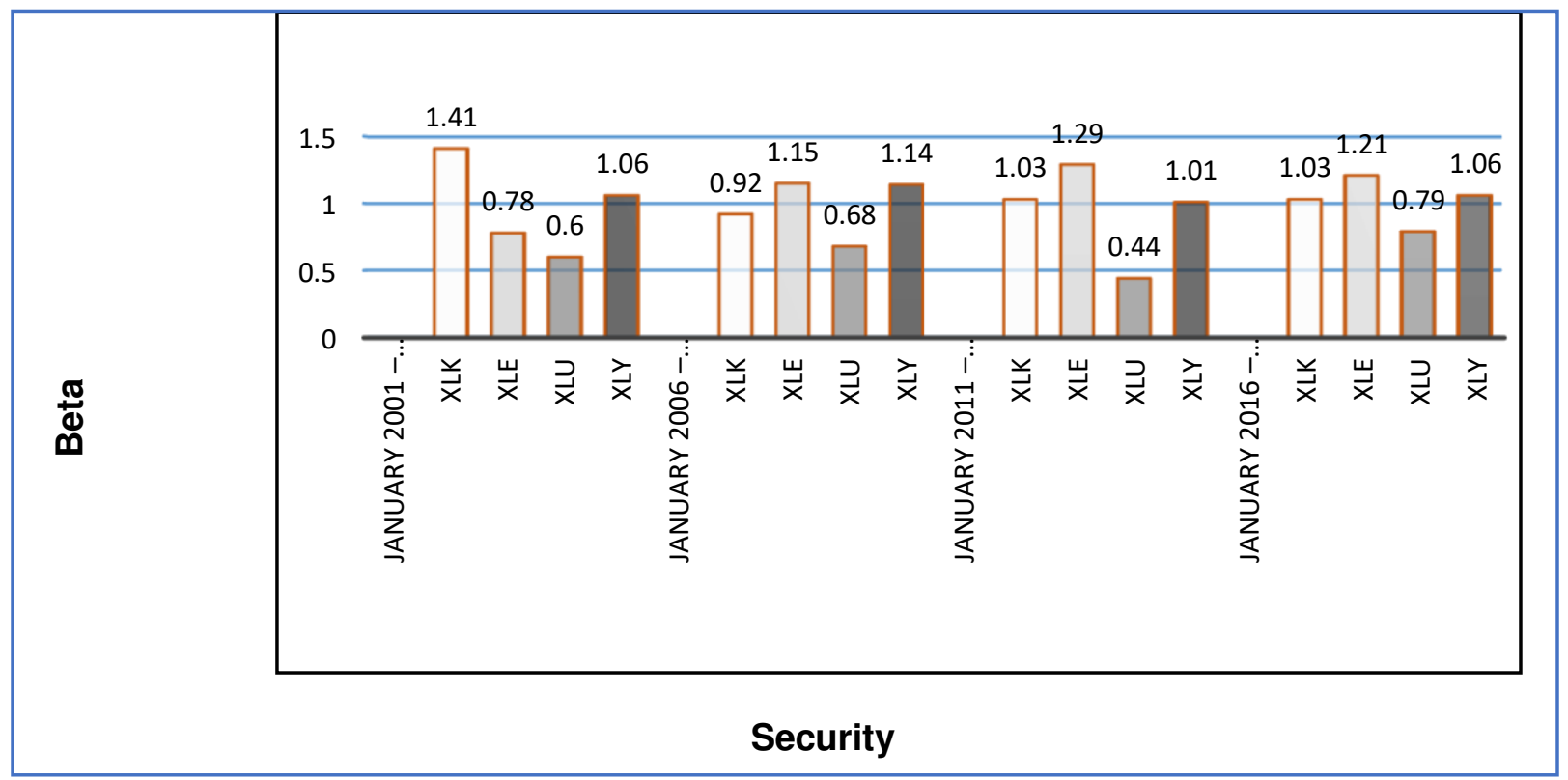

Note. Betas discovered by regressing monthly returns of security against S\&P 500 index.

\section{RQ2}

Estimated and observed betas were compared for statistical significance using a twotailed paired T-test for each ETF over the respective five-year periods. The results, as summarized in Table 2, illustrate failure to reject each of the twelve hypotheses, $\mathrm{H}_{0} 1, \mathrm{H}_{0} 2, \mathrm{H}_{0}$, $H_{0} 4, H_{0} 5, H_{0} 6, H_{0} 7, H_{0} 8, H_{0} 9, H_{0} 10, H_{0} 11$, and $H_{0} 12$, at the 0.05 significance level.

Figure 2 depicts the comparison of estimated and observed betas for each security over the three, five year periods. With respect to $\mathrm{XLK}$, the estimated and observed betas were close to 1 with the exception of the January 1 , 2006 - December 31, 2010 interval for which estimated beta was 1.41 and observed was 0.92 . The betas for XLE tended to be the highest but had wide variation; however, the differences between estimated and observed were small except for the perioid January 1, 2006 December 31, 2010 for which estimated beta was 0.78 and observed was 1.15.

XLU displayed the lowest betas; these were below 0.8 . Notably though, in two of the three periods, January 1, 2011 - December 31,
2015 and January 1, 2016 - December 31, 2020 the differences between estimated and observed were large, 0.24 and -0.35 respectively. The betas for XLY were surprisingly, above 1.0 for each period but notably the variances between estimated and observed betas were minimal. 


\section{Table 2}

Difference Between Estimated and Observed Betas Using Paired Sample T-Test

Security

January 2006 - December 2010 \& Preceding 5-

year period

XLK

XLE

$X L U$

$\mathrm{XLY}$

January 2011 - December 2015 \&

Preceding 5-year period

XLK

XLE

$X L U$

$X L Y$

January 2016 - December 2020 \&

Preceding 5-year period

$X L K$

XLE

$X L U$

$X L Y$

$\begin{array}{lll}2.00 & 258 & 0.47 \\ 2.00 & 258 & 0.89 \\ 2.00 & 258 & 1.00 \\ 2.00 & 258 & 1.00 \\ & & \\ 2.00 & 258 & 0.55 \\ 2.00 & 258 & 0.61 \\ 2.00 & 258 & 0.57 \\ 2.00 & 258 & 0.45 \\ & & \\ 2.00 & 258 & 0.24 \\ 2.00 & 258 & 0.93 \\ 2.00 & 258 & 0.91 \\ 2.00 & 258 & 0.92\end{array}$

$\overline{\text { Note. Pairs consisted of the returns for the noted five-year period and the prior five-year period. }}$

\section{Figure 2}

Estimated Versus Observed Betas

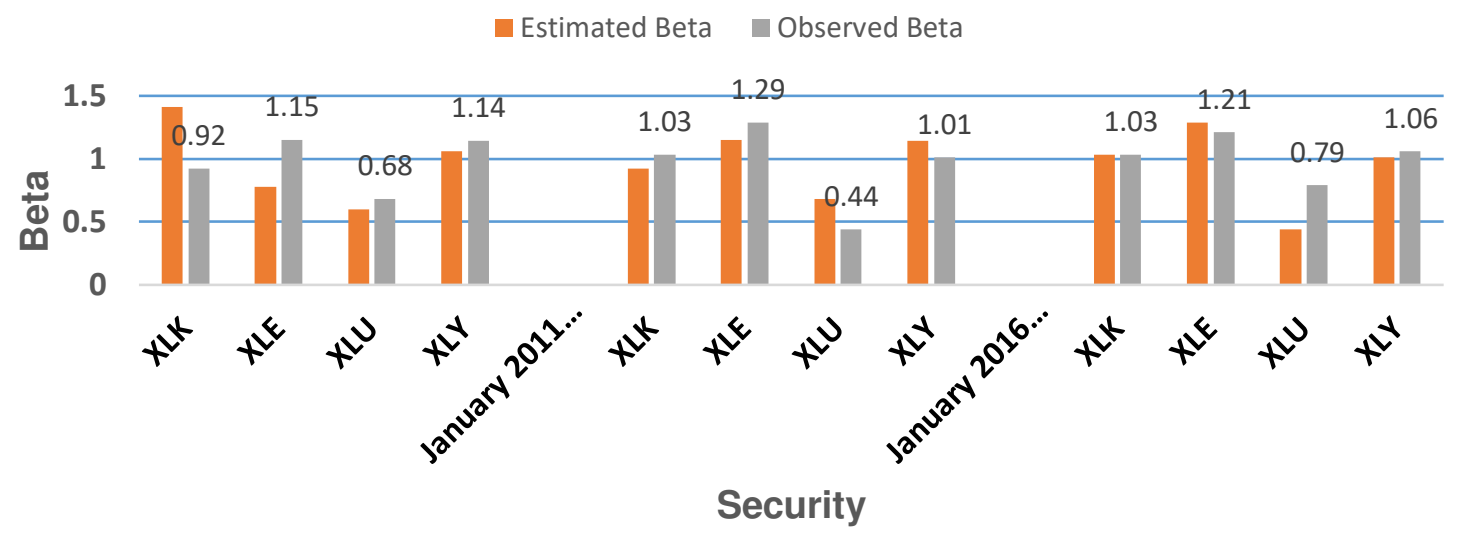

Note. Estimated and observed betas are compared for each security over three five-year periods. 


\section{RQ3}

For each of the four ETFs, the difference in annualized estimated returns using beta for the prior five years and those using actual returns was examined. To exemplify, the observed returns for the periods ending December 2006, 2007, 2008, 2009 and 2010 were compared to the analogous expected returns based on the single beta for the prior five-year period, January 1, 2001 to December 31,2005 . Returns over more than one year were annualized using the geometric mean. This was replicated for the two subsequent five-year periods ending December 2015 and 2020. Tables 3, 4, 5 and 6 tabulate the results and Figures 3, 4, 5 and 6 exhibit the differences between estimated and observed returns.

The expected returns for XLK, were in all years, excepting the one-year ending 2006, lower than those observed, and the differences were more pronounced in the five-year period ending December 31, 2020. With regard to XLE, there was significant variation within each fiveyear period. For example, in the five-year period ending December 31, 2010, the excess return from estimated beta over that from observed beta was close to zero over one and three years but $-50 \%$ and $-40 \%$ respectively over two and five years. For the five-year period ending December 31, 2015, the estimated return was lower by $17 \%$ over three years but greater by $18 \%$ over five years. For the five-year period ending December 31, 2020, the estimated return was lower by $14 \%$ over one year but greater by $43 \%$ over five years, while the differences over two, three, and four years were negative six, seven and four percent over two, three, and four years respectively.
For XLU, estimated minus observed returns were negative across all periods, with magnitude tending to be more pronounced in the five-years ending December 2015 and December 2020, with four returns showing values of $-60 \%$ or more for the difference. A similar but more pronounced pattern was noted for $\mathrm{XLY}$, and in this case, the differences in returns for the five-years ending December 2015 and December 2020 ranged from $-60 \%$ to $328 \%$ respectively. Moreover, the statistic for $\mathrm{XLY}$ was not only negative for all years but also of greater magnitude than for the other securities. 


\section{Figure 3}

Estimated Returns Versus Observed Returns for XLK

\section{XLK}

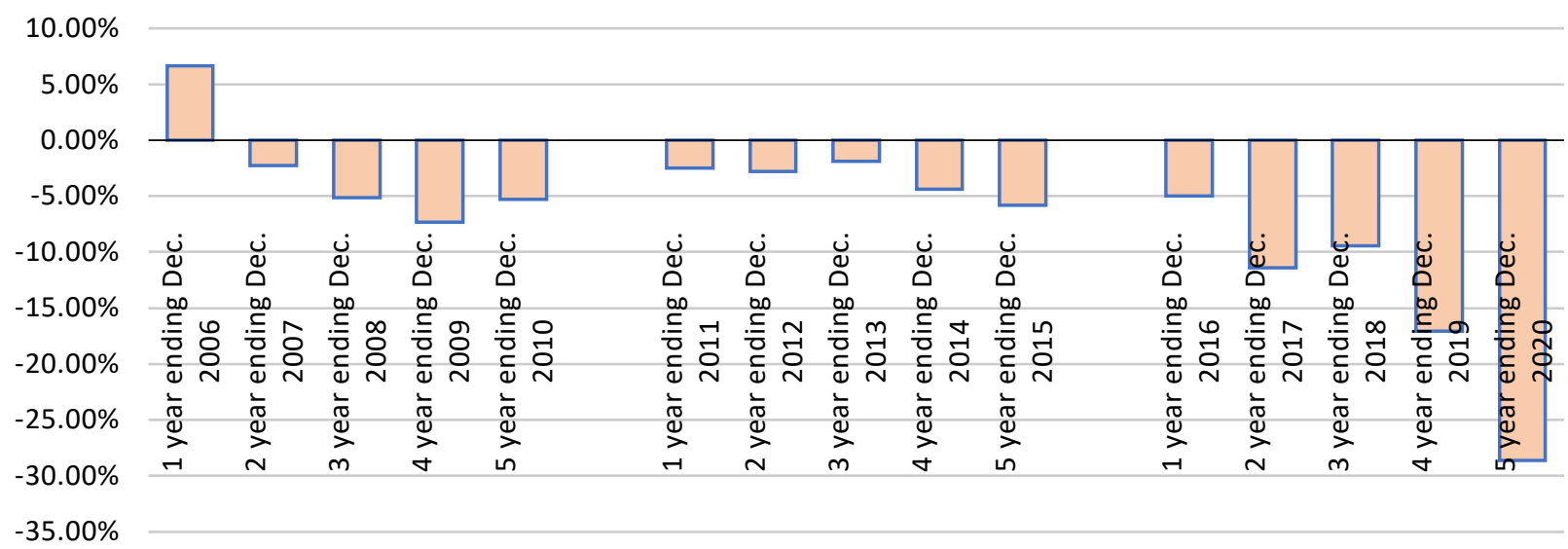

Note. Difference in annualized estimated returns using beta for prior five years and observed returns. Returns over more than one year were annualized using the geometric mean.

\section{Figure 4}

Estimated Returns Versus Observed Returns for XLE

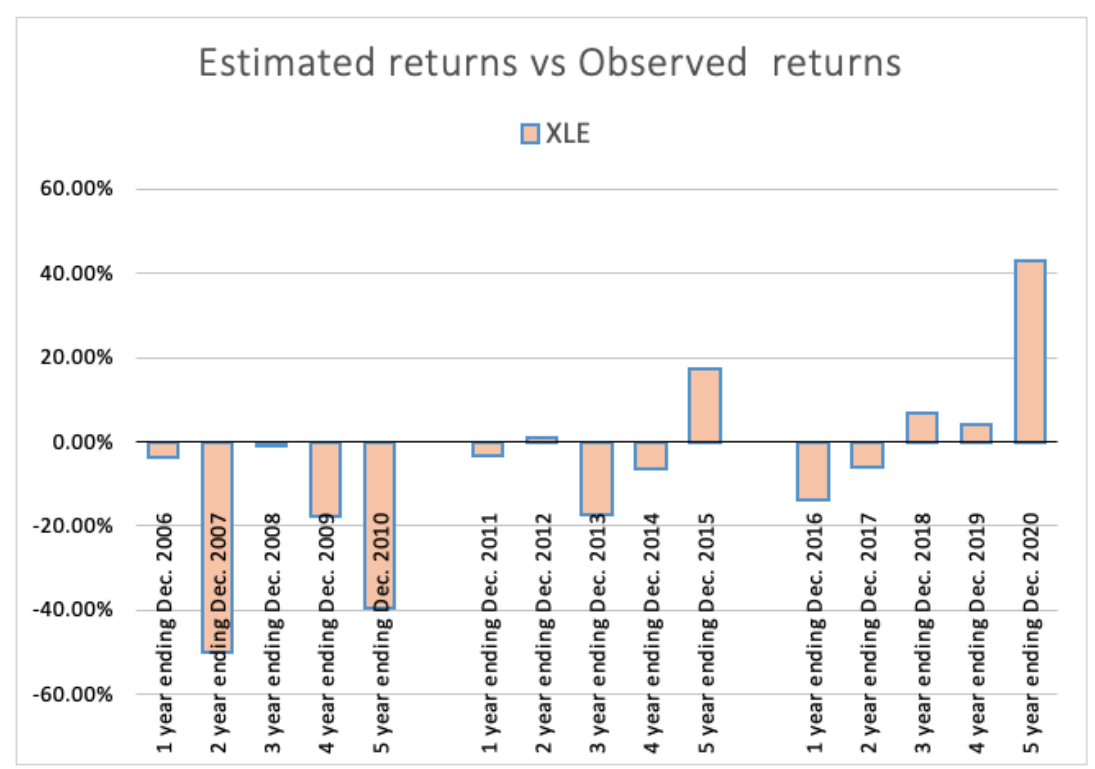

Note. Difference in annualized estimated returns using beta for prior five years and observed returns. Returns over more than one year were annualized using the geometric mean 


\section{Figure 5}

\section{Estimated Returns Versus Observed Returns for XLU}

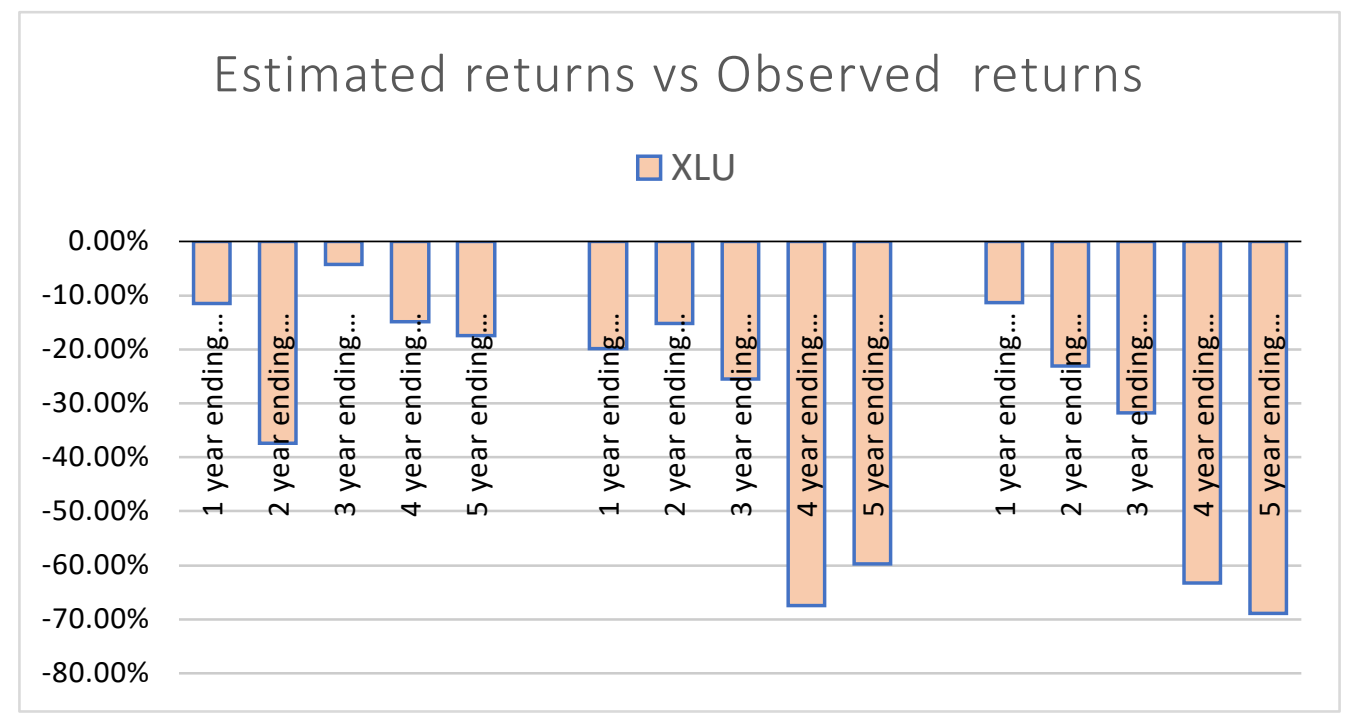

Note. Difference in annualized estimated returns using beta for prior five years and observed returns. Returns over more than one year were annualized using the geometric mean.

\section{Figure 6}

Estimated Returns Versus Observed Returns for XLU

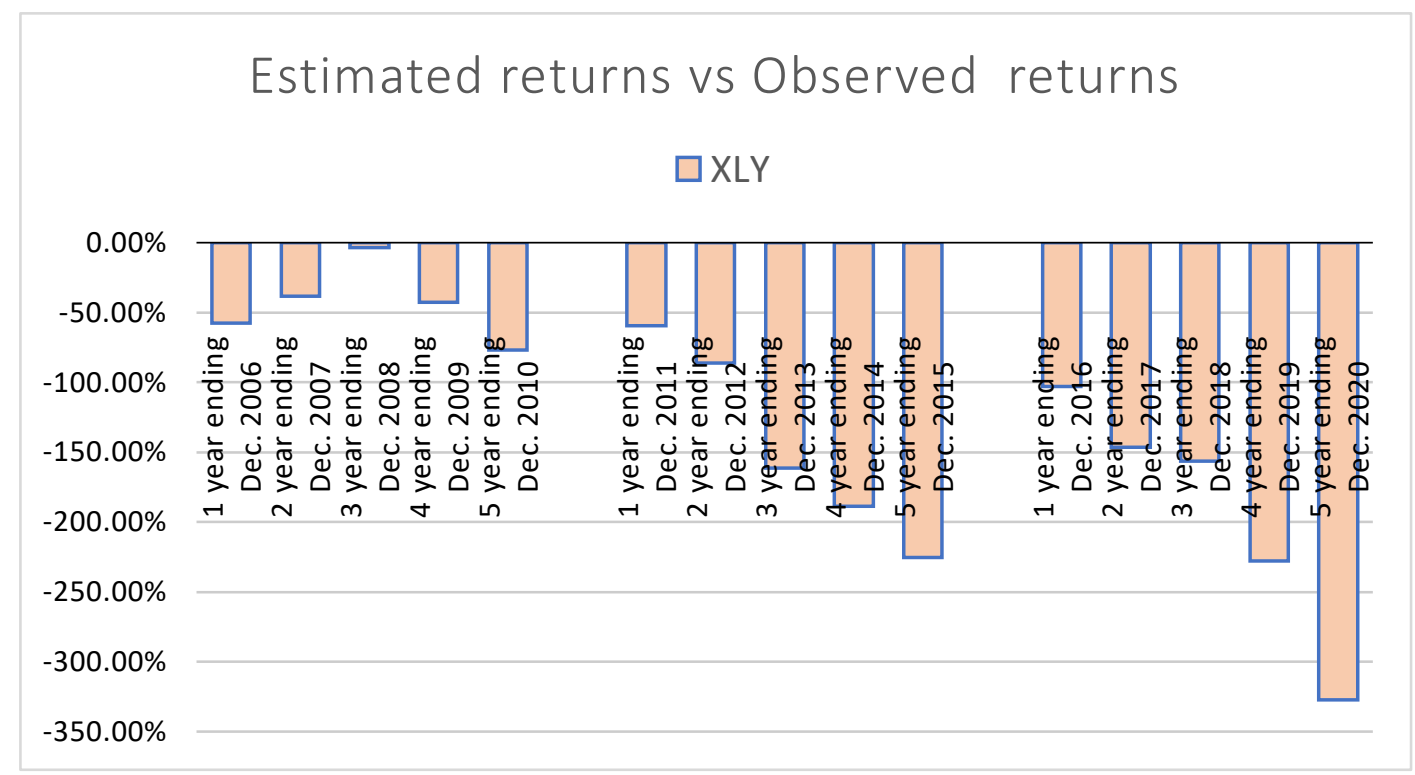

Note. Difference in annualized estimated returns using beta for prior five years and observed returns. Returns over more than one year were annualized using the geometric mean 


\section{RQ4}

The expected and actual returns depicted in Tables 3, 4, 5 and 6 were tested for statistical significance using a paired t-test to evaluate differences over the 15 year period for each security. The results, summarized in Table 7 , illustrate that at the 0.05 significance level, there was a failure to reject $\mathrm{H} 014$, but $\mathrm{H} 013$, $\mathrm{H} 015$, and $\mathrm{H} 016$ were rejected.

\section{Table 7}

Difference Between Returns Using Estimated Beta and Observed Returns for Years Ending 2006 to 2020 Using Paired Sample T-Test

\begin{tabular}{lccc}
\hline Security & $\mathrm{t}$ & $\mathrm{df}$ & $\begin{array}{c}\text { Sig. (2- } \\
\text { tailed) }\end{array}$ \\
\hline & & & \\
XLK & 2.15 & 14 & 0.005 \\
$\mathrm{XLE}$ & 2.15 & 14 & 0.33 \\
$\mathrm{XLU}$ & 2.15 & 14 & $<.001$ \\
$\mathrm{XLY}$ & 2.15 & 14 & $<.001$ \\
\hline \multicolumn{4}{l}{$\begin{array}{l}\text { Note. Returns over the entire 15-year period were tested } \\
\text { for statistical difference. }\end{array}$}
\end{tabular}

\section{RQ1}

\section{Discussion}

Figure 1 illustrates how each ETF's beta varied across the respective periods, and the betas can be evaluated against what was found in a recent study (Investment Fidelity, 2018). As expected, XLK representing the Information Technology sector consistently showed greater systematic risk than the market. XLE representing the Energy sector displayed a lower beta than the market contrary to expectations, for the first period ending December 2005 but exhibited a higher beta for the three subsequent periods as expected. The Utility sector XLU was consistently and significantly lower in systematic risk vis-à-vis the market and this was surprising as the difference was anticipated to be minimal. Perhaps the most surprising result pertained to XLY representing Consumer Staples, for which beta exceeded that of the market significantly and consistently when it was anticipated to actually have the lowest beta of the sectors and lower than that of the index. Baiocchi and Britt (2012), who argued that sectors are laggards or leaders depending on the cycle stage, display a wide range of volatilities across periods, and their inter correlations vary though they tend to converge during periods of market stress but can diverge during other periods. The results are therefore not surprising given this context.

RQ2

Each null hypothesis was rejected at the 0.05 significance level, suggesting that estimated beta is a good predictor of actual beta with regard to the samples and periods used. In practical terms though, this inference can be questioned as there were relatatively large variances in several instances between estimated and observed betas, and this would be a concern especially when investing large money sums.

RQ3

As relatatively large variances were observed between estimated and observed betas in relation to $R Q 2$, it would be anticipated that there would be even larger differences when returns at specific intervals were computed, and this appears to be the case. The expected returns were in all years, excepting the one-year ending 2006, greater than those observed for XLK, and the differences were more pronounced in the five-year period ending December 31, 2020.

With regard to $X L E$, there was significant variation within each five-year period. For example, in the five-year period ending December 31, 2005, the excess return from estimated beta over that from observed beta was close to zero over one and three years, but $40 \%$ or more over two and five years. For the five-year period ending December 31, 2005 and fourth years, the estimated return was lower by $14 \%$ over one year; whereas, the observed return was greater by $43 \%$ over five years, while the differences over two, three, and four years were negative six percent, seven percent, and four percent over two, three, and four years, respectively. In addition to the cyclical volatility described by Baiocchi and Britt (2012), sectors can be net transmitters of volatility or net receivers of volatility, and this may further explain some of these trends. Liu et al. (2021) contend that though most sectors act as transmitters or receivers at various stages, Consumer Staples, Materials and Energy are on the whole, receivers while Financial and Technology sectors are consistent transmitters of volatility. 
The study by Liu et al. (2012) did not include the Utilities sector while this study did not include the Financials sector. The Technology and Consumer Staples sectors represented by XLK and XLY respectively were part of both studies and can be discussed in terms of transmitted volatilities. The expected returns minus observed returns metric for XLK was positive for the year ending December 2006, and subsequently, turned negative, and overall with increasing magnitude for the subsequent years. However, for XLY, the metrics were not only negative for all years but also with greater magnitude than those of XLK. While the time involved for transmission to occur was not addressed by Liu et al. (2012), it is possible that the Technology sector had materially transmitted volatility to the Consumer Staples sector over the study interval, partly explaining the observations.

\section{RQ4}

The difference between returns predicted by beta and actual returns over 15 years were statistically significant at the 0.05 significance level for all securities with the exception of XLE. This suggests that over long periods of time, the investor could not rely on beta as a predictive measure of returns relative to the market for XLK, XLU and XLY. Further, even for XLE, for which rejection of null hypothesis failed, in practical terms, the variance between the returns estimated by beta and actual returns were large in many cases and may exceed the risk tolerance of many investors.

\section{Theoretical Implications}

These observations demonstrate that while the estimated beta, which is based on a historical return period, may be a good proxy for the actual beta for a future period, the practical value of applying estimated beta has limitations as the spread between returns estimated and those observed can change unpredictably both in direction and magnitude. This implies that the theoretical underpinnings behind how volatility of various segments of the market can change in relation to each other and to that of the market as a whole need to be studied in more depth. If estimation of beta can be refined, this metric would have more significance to both the individual investor who relies on it to forecast returns in relation to the market return and to the corporate sector that utilizes the CAPM equation to assess returns.

\section{Limitations and Future Directions}

Five-year periods were used to estimate beta, and as this is not static, different timeframes may have afforded alternate results. Further, returns were computed only at one-year intervals. More frequent intervals would afford a more complete picture. While highly diversified funds were employed, more sectors might be included beyond the four used. No corrective methods were used in beta-estimation, as the benefit of corrective techniques appears to be marginal and context-specific thus far. Beyond the returns and statistical tests used in this study to assess returns, additional statistics such as Value at Risk could be applied to evaluate, more completely, implications to the investor.

\section{Conclusion}

While the estimated betas were robust from a statistical standpoint, there was often variability across the five-year periods. However, they did conform largely to the anticipated systematic risk of each security, with the exception of XLY representing Consumer Staples, for which beta exceeded that of the market significantly and consistently. Beta, a measurement of systematic risk, should be indicative of returns in relation to the market. In an upward moving market, investors should expect higher returns with a larger value beta and lower returns in a downward moving one. The observations suggest that this is not consistently the case. Individual investors need to look at other metrics of risk in addition to beta to form a more cohesive view of expected returns from a portfolio.

\section{References}

Agarwal, K., Tanted, N. (2018). A study of "fundamental strength (alpha) and stock's sensitivity (beta)" of banking sector: Pre-post modi government formation. International Journal of Management and Research, 10(3), 56-66.

Anghel, M.-G., \& Paschia, L. (2013). Using the CAPM model to estimate the profitability of a financial instrument portfolio. Annales Universitatis Apulensis Series Oeconomica, 
15(2), 541-551.

Aygören, H., \& Saritaş, H. (2007). Is a correction necessary for beta estimation? Beta Tahmini Is a correction necessary for beta estimation? Beta tahmini için düzeltme gerekli mi? (14), 110-121.

Baiocchi, P., \& Britt, P. (2021). Sectors and style which is the better way to view the market? Journal of Indexes.

https://www.etf.com/docs/Sectors vs Size and Style Jol.pdf

Baltuttis, D., Töppel, J., Tränkler, T., \& Wiethe, C. (2020). Managing the risks of energy efficiency insurances in a portfolio context: An actuarial diversification approach. International Review of Financial Analysis, 68, 101-313. https://doi.org/10.1016/j.irfa.2019.01.007

Cenesizoglu, T., de Oliveira Ferrazoli Ribeiro, F., \& Reeves, J. J. (2017). Beta forecasting at long horizons. International Journal of Forecasting, 33(4), 936-957.

https://doi.org/10.1016/i.ijforecast.2017.06.004

Cenesizoglu, T., Liu, Q., Reeves, J. J., \& Wu, H. (2016). Monthly beta forecasting with low-, medium- and high-frequency stock returns. Journal of Forecasting, 35(6), 528-541. https://doi.org/10.1002/for.2396

Coppedge, W. T., Florida, N., Lamb, R. P., \& Mccague, J. E. (2012). Beta boot camp: Teaching students to properly apply systematic risk. Coggin College of Business, 3(7), 58-66.

Finch, J. H., Fraser, S. P., \& Scheff, S. R. (2011). Teaching the CAPM in the introductory finance course. Journal of Economics and Finance Education, 10(1), 77-82.

Frank, M. Z., \& Shen, T. (2016). Investment and the weighted average cost of capital. Journal of Financial Economics, 119(2), 300-315. https://doi.org/10.1016/i.jfineco.2015.09.001

Frazzini, A., \& Pedersen, L. H. (2014). Betting against beta. Journal of Financial Economics, 111(1), 1-25.

https://doi.org/10.1016/i.jfineco.2013.10.005

Graham, J. R., \& Harvey, C. R. (2001). The theory and practice of corporate finance: Evidence from the field. Journal of Financial Economics, 60(2-3), 187-243. https://doi.org/10.1016/S0304-405X(01)00044-7
Groenewold, N., \& Fraser, P. (2000).

Forecasting beta: How well does the "five-year rule of thumb" do? Journal of Business Finance and Accounting, 27(7-8), 953-982.

https://doi.org/10.1111/1468-5957.00341

Investment Fidelity. (2018). Investing in equities with sectors. Fidelity Brokerage Services LLC. Kaplan, P. D., \& Peterson, J. D. (1998). Fullinformation industry betas. Financial Management, 27(2), 85. https://doi.org/10.2307/3666295

Khan, H. ur R., Khidmat, W., Bin, \& Awan, S. (2021). Board diversity, financial flexibility and corporate innovation: Evidence from China. Eurasian Business Review, 11(2), 303-326. https://doi.org/10.1007/s40821-020-00171-9

Lettau, M., \& Madhavan, A. (2018). Exchangetraded funds 101 for economists. Journal of Economic Perspectives, 32(1), 135-153. https://doi.org/10.1257/iep.32.1.135

Liu, P., Power, G. J., \& Vedenov, D. (2021). Fair-weather friends? Sector-specific volatility connectedness and transmission. International Review of Economics \& Finance, 76, 712-736. https://doi.org/10.1016/j.iref.2021.06.004

Löffler, G., \& Raupach, P. (2018). Pitfalls in the use of systemic risk measures. Journal of Financial and Quantitative Analysis, 53(1), 269298.

https://doi.org/10.1017/S0022109017001041

Nielson, D., Nielsen, F., \& Barnes, B. (2016). An overview of factor investing. Leadership Series, 1, 1-8. https://www. fidelity.com/binpublic/060 www fidelity com/documents/fidelity /fidelity-overview-of-factor-investing.pdf

O'Sullivan, P. (2018). The capital asset pricing model and the efficient markets hypothesis: The compelling fairy tale of contemporary financial economics. International Journal of Political Economy, 47(3-4), 225-252.

https://doi.org/10.1080/08911916.2018.1517462

Verma, R., Soydemir, G., \& Huang, T. M. (2020). Are smart beta funds really smart? Evidence from rational and quasi-rational investor sentiment data. Review of Behavioral Finance, 12(2), 97-118. https://doi.org/10.1108/RBF-08-2018-0084 


\section{Appendix A}

Table 3

Difference Between Returns Estimated by Beta and Observed Returns Over Selected Periods for $X L K$

\begin{tabular}{|c|c|c|c|c|}
\hline Period & Security & $\begin{array}{c}\text { Estimated } \\
\text { Annualized } \\
\text { Return }\end{array}$ & $\begin{array}{c}\text { Observed } \\
\text { Annualized } \\
\text { Return }\end{array}$ & $\begin{array}{l}\text { Expected } \\
\text { Minus } \\
\text { Observed } \\
\text { Return }\end{array}$ \\
\hline 1 year ending December 2006 & XLK & $16.65 \%$ & $9.98 \%$ & $6.67 \%$ \\
\hline 2 year ending December 2007 & XLK & $11.68 \%$ & $13.97 \%$ & $-2.29 \%$ \\
\hline 3 year ending December 2008 & XLK & $-14.04 \%$ & $-8.88 \%$ & $-5.16 \%$ \\
\hline 4 year ending December 2009 & XLK & $-3.96 \%$ & $3.35 \%$ & $-7.31 \%$ \\
\hline 5 year ending December 2010 & XLK & $-0.24 \%$ & $5.07 \%$ & $-5.31 \%$ \\
\hline 1 year ending December 2011 & XLK & $-1.03 \%$ & $1.48 \%$ & $-2.51 \%$ \\
\hline 2 year ending December 2012 & XLK & $4.71 \%$ & $7.51 \%$ & $-2.80 \%$ \\
\hline 3 year ending December 2013 & XLK & $13.69 \%$ & $15.57 \%$ & $-1.88 \%$ \\
\hline 4 year ending December 2014 & XLK & $14.59 \%$ & $18.99 \%$ & $-4.40 \%$ \\
\hline 5 year ending December 2015 & XLK & $11.43 \%$ & $17.23 \%$ & $-5.80 \%$ \\
\hline 1 year ending December 2016 & XLK & $11.54 \%$ & $16.55 \%$ & $-5.01 \%$ \\
\hline 2 year ending December 2017 & XLK & $16.86 \%$ & $28.23 \%$ & $-11.37 \%$ \\
\hline 3 year ending December 2018 & XLK & $8.05 \%$ & $17.46 \%$ & $-9.42 \%$ \\
\hline 4 year ending December 2019 & XLK & $15.42 \%$ & $32.45 \%$ & $-17.03 \%$ \\
\hline 5 year ending December 2020 & XLK & $17.55 \%$ & $46.12 \%$ & $-28.58 \%$ \\
\hline
\end{tabular}

Note. Observed returns were compared with those estimated based on the beta for the prior five years. Returns

over more than one year were annualized using the geometric mean.

Table 4

Difference Between Returns Estimated by Beta and Observed Returns Over Selected Periods for XLE

\begin{tabular}{|c|c|c|c|c|}
\hline Period & Security & $\begin{array}{c}\text { Estimated } \\
\text { Annualized } \\
\text { Return }\end{array}$ & $\begin{array}{l}\text { Observed } \\
\text { Annualized } \\
\text { Return }\end{array}$ & $\begin{array}{c}\text { Expected } \\
\text { Minus } \\
\text { Observed } \\
\text { Return }\end{array}$ \\
\hline 1 year ending December 2006 & XLE & $9.19 \%$ & $12.71 \%$ & $-3.52 \%$ \\
\hline 2 year ending December 2007 & XLE & $6.44 \%$ & $56.26 \%$ & $-49.81 \%$ \\
\hline 3 year ending December 2008 & XLE & $-7.75 \%$ & $-6.82 \%$ & $-0.93 \%$ \\
\hline 4 year ending December 2009 & XLE & $-2.19 \%$ & $15.59 \%$ & $-17.78 \%$ \\
\hline 5 year ending December 2010 & XLE & $-0.13 \%$ & $39.43 \%$ & $-39.56 \%$ \\
\hline 1 year ending December 2011 & XLE & $-1.29 \%$ & $2.06 \%$ & $-3.35 \%$ \\
\hline 2 year ending December 2012 & XLE & $5.89 \%$ & $5.01 \%$ & $0.88 \%$ \\
\hline 3 year ending December 2013 & XLE & $17.11 \%$ & $34.28 \%$ & $-17.17 \%$ \\
\hline 4 year ending December 2014 & XLE & $18.23 \%$ & $24.75 \%$ & $-6.53 \%$ \\
\hline 5 year ending December 2015 & XLE & $14.28 \%$ & $-3.23 \%$ & $17.51 \%$ \\
\hline 1 year ending December 2016 & XLE & $14.46 \%$ & $28.07 \%$ & $-13.60 \%$ \\
\hline 2 year ending December 2017 & XLE & $21.13 \%$ & $26.93 \%$ & $-5.80 \%$ \\
\hline 3 year ending December 2018 & XLE & $10.08 \%$ & $3.26 \%$ & $6.82 \%$ \\
\hline 4 year ending December 2019 & XLE & $19.32 \%$ & $15.34 \%$ & $3.98 \%$ \\
\hline 5 year ending December 2020 & XLE & $21.99 \%$ & $-21.23 \%$ & $43.22 \%$ \\
\hline
\end{tabular}


Table 5

Difference Between Returns Estimated by Beta and Observed Returns Over Selected Periods for $X L U$

\begin{tabular}{|c|c|c|c|c|}
\hline & & $\begin{array}{l}\text { Estimated } \\
\text { Annualized }\end{array}$ & $\begin{array}{l}\text { Observed } \\
\text { Annualized }\end{array}$ & $\begin{array}{c}\text { Minus } \\
\text { Observed }\end{array}$ \\
\hline Period & Security & Return & Return & Return \\
\hline 1 year ending December 2006 & XLU & $7.06 \%$ & $18.62 \%$ & $-11.56 \%$ \\
\hline 2 year ending December 2007 & XLU & $4.95 \%$ & $42.41 \%$ & $-37.46 \%$ \\
\hline 3 year ending December 2008 & XLU & $-5.95 \%$ & $-1.74 \%$ & $-4.21 \%$ \\
\hline 4 year ending December 2009 & $\mathrm{XLU}$ & $-1.68 \%$ & $13.12 \%$ & $-14.80 \%$ \\
\hline 5 year ending December 2010 & XLU & $-0.10 \%$ & $17.42 \%$ & $-17.52 \%$ \\
\hline 1 year ending December 2011 & XLU & $-0.77 \%$ & $19.05 \%$ & $-19.82 \%$ \\
\hline 2 year ending December 2012 & XLU & $3.51 \%$ & $18.68 \%$ & $-15.17 \%$ \\
\hline 3 year ending December 2013 & XLU & $10.20 \%$ & $35.75 \%$ & $-25.55 \%$ \\
\hline 4 year ending December 2014 & XLU & $10.87 \%$ & $78.32 \%$ & $-67.46 \%$ \\
\hline 5 year ending December 2015 & XLU & $8.51 \%$ & $68.27 \%$ & $-59.76 \%$ \\
\hline 1 year ending December 2016 & XLU & $4.96 \%$ & $16.32 \%$ & $-11.37 \%$ \\
\hline 2 year ending December 2017 & XLU & $7.25 \%$ & $30.32 \%$ & $-23.07 \%$ \\
\hline 3 year ending December 2018 & XLU & $3.46 \%$ & $35.23 \%$ & $-31.77 \%$ \\
\hline 4 year ending December 2019 & XLU & $6.63 \%$ & $69.91 \%$ & $-63.28 \%$ \\
\hline 5 year ending December 2020 & XLU & $0.00 \%$ & $68.93 \%$ & $-68.93 \%$ \\
\hline
\end{tabular}

Note. Observed returns were compared with those estimated based on the beta for the prior five years. Returns over more than one year were annualized using the geometric mean.

Table 6

Difference Between Returns Estimated by Beta and Observed Returns Over Selected Periods

for $X L Y$

\begin{tabular}{|c|c|c|c|c|}
\hline \multirow{5}{*}{ Period } & \multirow{5}{*}{ Security } & \multicolumn{3}{|r|}{ Expected } \\
\hline & & Estimated & Observed & Minus \\
\hline & & Annualized & Annualized & Observe \\
\hline & & Return & Return & d \\
\hline & & & & Return \\
\hline 1 year ending December 2006 & XLU & $12.43 \%$ & $70.01 \%$ & $-57.58 \%$ \\
\hline 2 year ending December 2007 & XLU & $8.71 \%$ & $47.31 \%$ & $-38.59 \%$ \\
\hline 3 year ending December 2008 & XLU & $-10.48 \%$ & $-6.86 \%$ & $-3.62 \%$ \\
\hline 4 year ending December 2009 & $\mathrm{XLU}$ & $-2.96 \%$ & $39.58 \%$ & $-42.53 \%$ \\
\hline 5 year ending December 2010 & $\mathrm{XLU}$ & $-0.18 \%$ & $76.65 \%$ & $-76.83 \%$ \\
\hline 1 year ending December 2011 & XLU & $-1.28 \%$ & $58.30 \%$ & $-59.58 \%$ \\
\hline 2 year ending December 2012 & XLU & $5.84 \%$ & $91.84 \%$ & $-85.99 \%$ \\
\hline 3 year ending December 2013 & $\mathrm{XLU}$ & $16.98 \%$ & $178.18 \%$ & $-161.20 \%$ \\
\hline 4 year ending December 2014 & $\mathrm{XLU}$ & $18.09 \%$ & $206.96 \%$ & $-188.87 \%$ \\
\hline 5 year ending December 2015 & XLU & $14.17 \%$ & $239.39 \%$ & $-225.22 \%$ \\
\hline 1 year ending December 2016 & XLU & $11.37 \%$ & $114.30 \%$ & $-102.93 \%$ \\
\hline 2 year ending December 2017 & XLU & $16.61 \%$ & $163.21 \%$ & $-146.60 \%$ \\
\hline 3 year ending December 2018 & XLU & $7.93 \%$ & $164.55 \%$ & $-156.62 \%$ \\
\hline 4 year ending December 2019 & XLU & $15.19 \%$ & $242.78 \%$ & $-227.59 \%$ \\
\hline 5 year ending December 2020 & XLU & $17.29 \%$ & $344.75 \%$ & $-327.47 \%$ \\
\hline
\end{tabular}

